\title{
Sustained postoperative plasma elevations of plasminogen activator inhibitor-1 following minimally invasive colorectal cancer resection
}

\author{
H.M.C. SHANTHA KUMARA ${ }^{1}$, POPPY ADDISON ${ }^{1}$, DASUNI N. GAMAGE ${ }^{2}$, ERICA PETTKE ${ }^{3}$, \\ ABHINIT SHAH $^{1}$, XIAOHONG YAN ${ }^{1}$, VESNA CEKIC ${ }^{1}$ and RICHARD L. WHELAN ${ }^{1,4}$ \\ ${ }^{1}$ Division of Colon and Rectal Surgery, Department of Surgery, Lenox Hill Hospital, \\ Northwell Health, New York, NY 10028; ${ }^{2}$ Nuvance Health, Vassar Brothers Medical Center, \\ Poughkeepsie, NY 12601; ${ }^{3}$ Department of Surgery, Swedish Medical Center, Seattle, WA 98122; \\ ${ }^{4}$ Donald and Barbara Zucker School of Medicine at Hofstra/Northwell, Hempstead, NY 11549, USA
}

Received February 1, 2021; Accepted September 2, 2021

DOI: $10.3892 / \mathrm{mco} .2021 .2461$

\begin{abstract}
Plasminogen activator inhibitor-1 (PAI-1) is a serine protease inhibitor that inhibits urokinase-type plasminogen activator and tissue-type plasminogen activator. PAI-1 participates in angiogenesis, wound healing and tumor invasion, and additionally regulates endothelial cell proliferation, angiogenesis and tumor growth. The purpose of the present study was to measure plasma PAI-1 levels perioperatively in patients with colorectal cancer (CRC) undergoing minimally invasive colorectal resection (MICR). Patients with CRC who underwent elective MICR were eligible for the study. All patients were enrolled in an approved data/plasma bank. Patients with preoperative, postoperative day (POD) 1, POD 3, and at least one POD 7-34 plasma sample collection were studied. Plasma PAI-1 levels were determined in duplicate using ELISA, and the medians and 95\% confidence intervals (CIs) were determined. The correlations between postoperative
\end{abstract}

Correspondence to: Professor Richard L. Whelan, Division of Colon and Rectal Surgery, Department of Surgery, Lenox Hill Hospital, Northwell Health, 1421 Third Avenue, Suite PH, New York, NY 10028, USA

E-mail: rwhelan1@northwell.edu

Abbreviations: MICR, minimally invasive colorectal resection; CRC, colorectal cancer; PAI-1, plasminogen activator inhibitor-1; uPA, urokinase-type plasminogen activator; tPA, tissue-type plasminogen activator; EC, endothelial cell; POD, postoperative day; VEGF, vascular endothelial growth factor; PLGF, placental growth factor; ANG2, angiopoetin-2; MCP-1, monocyte chemoattractant protein-1; CHI3L1, chitinase 3-like protein-1; OPN, osteopontin; sVCAM-1, soluble vascular adhesion molecule-1; CXCL16, chemokine (C-X-C motif) ligand 16; ECM, extracellular matrix; ns, not significant

Key words: plasminogen activator inhibitor-1, postoperative plasma levels, colorectal surgery plasma PAI-1 levels and length of surgery were evaluated. PAI-1 levels were compared between patients who underwent laparoscopic-assisted vs. hand-assisted surgery. The preoperative PAI-1 levels of stage I, II, III and IV pathological stage subgroups were also compared. A total of 91 patients undergoing MICR for CRC were studied. The mean incision length was $8.0 \pm 3.9 \mathrm{~cm}$, and the length of stay was $6.8 \pm 4.3$ days. Compared with the median preoperative levels $(17.30 ; 95 \% \mathrm{CI}$ : $15.63-19.78 \mathrm{ng} / \mathrm{ml}$ ), significantly elevated median levels were observed on POD 1 (28.86; 95\% CI: $25.46-31.22 \mathrm{ng} / \mathrm{ml}$; $\mathrm{P}<0.001)$, POD 3 (18.87; 95\% CI: 17.05-21.78 ng $/ \mathrm{ml} ; \mathrm{P}=0.0037$ ), POD 7-13 (26.97; 95\% CI: 22.81-28.74 ng/ml; P<0.001), POD 14-20 (25.92; 95\% CI: $17.85-35.89 \mathrm{ng} / \mathrm{ml} ; \mathrm{P}=0.001)$ and POD 21-27 (22.63; 95\% CI: 20.03-30.09 ng/ml; P<0.001). The PAI-1 levels in the hand-assisted group were higher compared with those in the laparoscopic-assisted group for 4 weeks after surgery; however, a significant difference was found only on POD 1 . Therefore, plasma PIA-1 levels were found to be significantly elevated for 4 weeks after MICR, and the surgery-related acute inflammatory response may account for the early postoperative PIA-1 increase. Furthermore, PAI-1-associated VEGF-induced angiogenesis in the healing wounds may account for the late postoperative elevations, and increased PAI-1 levels may promote angiogenesis in residual tumor deposits.

\section{Introduction}

The recurrence rate after curative colorectal cancer (CRC) resection ranges between 20 and $40 \%$ (1). Recurrence may develop from microscopic residual disease or successfully implanted circulating tumor cells released during surgery. Strong experimental (and weaker clinical) evidence suggests that tumor growth is stimulated during the early postoperative period (2-6). As adjuvant therapy is not initiated for 4-6 weeks after surgery, the postoperative period may be hazardous for patients with cancer who harbor residual tumors. Due to these concerns, efforts have been made to identify anticancer treatments that can be administered perioperatively (7-9). 
Several mechanisms have been proposed to explain the enhanced tumor growth noted after surgery, including cell-mediated immunosuppression, decreased blood levels of tumor growth-suppressing proteins, and removal of primary tumor-associated metastasis-suppressing factors (10-12).

Moreover, the plasma levels of at least 10 proteins [VEGF, angiopoietin-2 (Ang-2), placental growth factor (PIGF), soluble vascular adhesion molecule-1 (sVCAM-1), IL-8, monocyte chemoattractant protein-1 (MCP-1), chitinase 3-like protein-1 (CHI3L1), MMP-3 and chemokine [C-X-C motif] ligand 16 (CXCL-16)] with proangiogenic effects have been shown to be significantly elevated over the preoperative baseline concentrations for 3-5 weeks after minimally invasive colorectal resection (MICR) (3-5,13-17). Postoperative plasma collected on the second and third weeks after MICR has been shown to significantly increase endothelial cell (EC) proliferation, invasion and migration (key components of angiogenesis) in vitro, compared with the results obtained with preoperative plasma (3-5,13-19). These findings have raised concerns that the growth of residual cancer deposits may be facilitated during the first month after curative cancer resection via accelerated tumor angiogenesis due to these systemic plasma protein alterations. These results have also led to further efforts to characterize the effects of surgery on the plasma levels of other proteins that may affect angiogenesis and tumor growth (6,20-21). The present study focused on one of these proteins, plasminogen activator inhibitor-1 (PAI-1).

PAI-1 is a serine protease inhibitor (serpin) that inhibits tissue plasminogen activator (tPA) and urokinase plasminogen activator (uPA), thereby preventing the conversion of plasminogen to plasmin and subsequent fibrinolysis (22). Plasmin is an antithrombotic agent that plays a critical role in maintaining blood vessel patency and in the proliferative phase of wound healing. Plasmin breaks down the fibrin clots initially laid down in wounds, and facilitates macrophage and fibroblast entry into the wounds and the subsequent generation of collagen (23). PAI-1 regulates fibrinolysis and is involved in the wound healing process, and its plasma levels may be elevated during the perioperative period. PAI-1 also affects angiogenesis via its extracellular matrix (ECM) proteolytic and cell migration/adhesion effects (24). PAI-1 is a single-chain glycoprotein with a short plasma half-life, and its plasma levels typically range between 6 and $80 \mathrm{ng} / \mathrm{ml}$ (25). Excessive PAI-1 levels and dysregulated fibrinolysis may lead to pathogenic thrombosis. Elevated expression levels of PAI-1 have been reported in rectal cancer and were found to be directly associated with cancer stage (26). Elevated plasma levels of PAI-1 have also been associated with worse outcomes in lung, breast, and stomach cancer, as well as CRC (27-32). A growing body of evidence suggests that PAI-1 facilitates tumor cell proliferation, tumor angiogenesis, and other tumorigenic effects (33).

The effects of colorectal surgery on plasma PAI-1 levels are currently unknown. Therefore, the purpose of the present study was to compare PAI-1 levels before and at 5 weeks after minimally invasive surgical resection of CRC.

\section{Materials and methods}

Study population. Study patients were selected from a population of patients with CRC undergoing MICR who had been enrolled in an institutional review board-approved prospective perioperative tissue and data bank at Mount Sinai West Hospital or New York-Presbyterian Hospital between 2006 and 2015 (IRB reference no. GCO1: 16-2619-Institutional Review Board of the Mount Sinai School of Medicine, New York, USA; and IRB reference no. AAAA4473-Institutional Review Board of the Columbia University Medical Center, New York, USA). In addition to banking samples of tumor and normal colonic mucosa, preoperative and multiple postoperative blood samples were obtained. The blood samples were quickly processed after collection, and the plasma was harvested, divided into aliquots and stored at $-80^{\circ} \mathrm{C}$ until use. The purpose of this protocol was to evaluate the physiological, immunological and oncological effects of MICR. Only patients who underwent surgery alone were eligible; those who were treated with a novel drug or underwent other procedures were excluded. Immunosuppressed patients and patients who received perioperative blood transfusion(s) were also excluded, as were patients undergoing urgent or emergent surgery. Only patients for whom blood samples had been taken preoperatively, on postoperative day (POD) 1 or 3 , and at least one sampling point beyond POD 7, were considered as eligible. Since post-discharge blood samples were not obtained on particular PODs, and since the late specimens were collected over a 3-4-week period, the late samples were bundled into 7-day blocks (POD 7-13, POD 14-20, POD 21-27 and POD 28-34) that were considered at single time points in the data analysis. Post-hospital discharge blood sampling was performed during follow-up hospital visits.

Blood sampling and processing. Blood samples were obtained preoperatively, at POD 1 or POD 3, and at least one late time point (POD 7-34). Blood samples were drawn into heparin-containing blood collection tubes and processed within 5-6 h. The plasma samples were isolated via centrifugation $\left(450 \mathrm{x} \mathrm{g}\right.$ for $10 \mathrm{~min}$ at $\left.6^{\circ} \mathrm{C}\right)$ and stored in $500-\mu 1$ aliquots at $-80^{\circ} \mathrm{C}$ until analysis.

PAI-1 determination. Plasma PAI-1 levels were determined in duplicate using a commercially available ELISA kit (cat no. DSE100; R\&D Systems, Inc.) according to the manufacturer's instructions. Plasma PAI-1 concentrations are reported as $\mathrm{ng} / \mathrm{ml}$.

Statistical analysis. Continuous random variables such as age, operative time, length of stay and surgical incision are presented as mean $\pm \mathrm{SD}$, whereas categorical variables are presented as frequencies and percentages. As previously mentioned, late samples were bundled into 7-day blocks that were considered as single time points for the data analysis. Since preoperative and corresponding postoperative PAI-1 values were not normally distributed at later time points, the comparison of PAI-1 values for the preoperative vs. postoperative time points was performed using the non-parametric Wilcoxon signed-rank paired test, and the data are reported as medians and 95\% confidence intervals (CIs). The data are depicted in bar graphs expressing PAI-1 levels as medians and $75 \%$ quartile ranges. Comparisons between hand-assisted and laparoscopic-assisted subgroups, male and female patients, and among preoperative PAI-1 levels of stage I, II, III and 
Table I. Demographic and clinical characteristics of the study population.

\begin{tabular}{lc}
\hline Characteristics & No. $(\%)$ \\
\hline Age, years (mean \pm SD) & $67.3 \pm 13.6$ \\
Sex & \\
Male & $45(49.0)$ \\
Female & $46(51.0)$ \\
Incision length, cm (mean \pm SD) & \\
Entire patient population & $8.0 \pm 3.9$ \\
Leg procedure group & $6.6 \pm 3.6$ \\
Hand procedure group & $10.2 \pm 3.2$ \\
Operative time, min (mean \pm SD) & $318.2 \pm 128.5$ \\
Length of stay, days (mean \pm SD) & $6.8 \pm 4.3$ \\
Type of resection & \\
Right & $32(35.0)$ \\
Low anterior resection/anterior & $18(20.0)$ \\
resection (16/2) & \\
Sigmoid/rectosigmoid (11/6) & $17(19.0)$ \\
Total/subtotal (2/7) & $10(9.0)$ \\
Transverse & $6(7.0)$ \\
Left & $6(7.0)$ \\
Abdominoperineal resection & $3(3.0)$ \\
Surgical method & \\
Laparoscopic-assisted & $59(65.0)$ \\
Hand-assisted/hybrid laparoscopic & $32(35.0)$ \\
\hline
\end{tabular}

IV subgroups were performed using the non-parametric Mann-Whitney U test. Correlation between the postoperative plasma PAI-1 levels and the patient age and operative time were performed using Spearman's correlation coefficient (rs). $\mathrm{P}<0.05$ was considered to indicate a statistically significant difference. All analyses were performed using SPSS, version 15.0 (SPSS, Inc.).

\section{Results}

Clinicopathological characteristics. A total of 91 patients with CRC who underwent MICR were selected for the present study. The patients comprised 45 men and 46 women, with a mean age of $67.3 \pm 13.6$ years (range, $40-93$ years). The breakdown of the types of resection performed is displayed in Table I. The most commonly performed procedures were right hemicolectomy (35\%), low anterior resection or anterior resection (20\%), and sigmoid resection (19\%). Laparoscopic-assisted surgery (mean incision length, $6.6 \pm 3.6 \mathrm{~cm}$ ) was performed in $65 \%$ of the patients, whereas hand-assisted laparoscopic surgery (mean incision size, $10.2 \pm 3.2 \mathrm{~cm}$ ) was performed in $35 \%$ of the patients. The mean operative time was $318.2 \pm 128.5 \mathrm{~min}$. The mean length of hospital stay was $6.8 \pm 4.3$ days. The postoperative complications included the following: Ileus $(n=5)$, urinary tract infection $(n=5)$, diarrhea $(n=4)$, atelectasis $(n=2)$, seroma $(n=1)$ and phlebitis $(n=1)$. There were no superficial, deep, or organ-space surgical site infections, or deaths. The

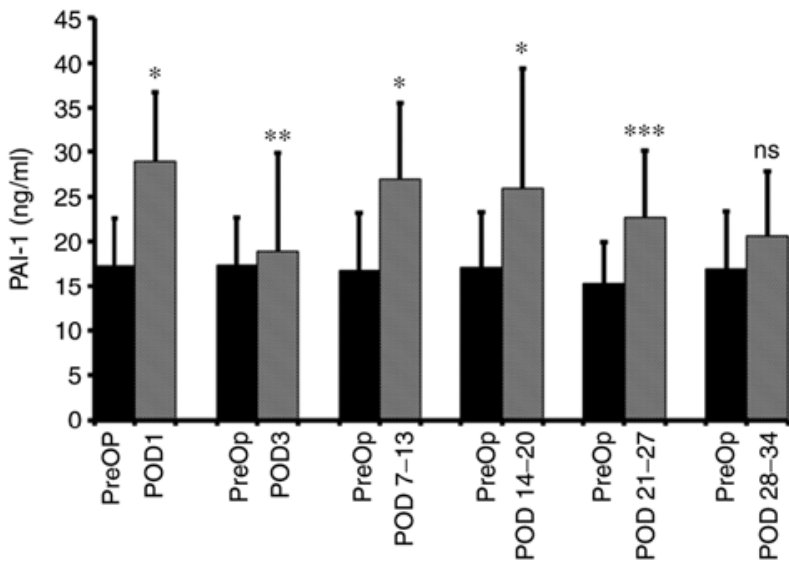

Figure 1. PreOp and postoperative plasma PAI-1 levels in patients with colorectal cancer were determined using ELISA. PAI-1 levels are expressed as median and $75 \%$ quartile range. "PreOp vs. POD $1(\mathrm{n}=91 ; \mathrm{P}<0.001)$; ${ }^{* *}$ PreOp vs. POD 3 ( $\left.\mathrm{n}=86 ; \mathrm{P}=0.0037\right) ;{ }^{*}$ PreOp vs. POD 7-13 ( $\left.\mathrm{n}=65 ; \mathrm{P}<0.001\right)$; ${ }^{* * * *}$ PreOp vs. POD 14-20 ( $\left.\mathrm{n}=26 ; \mathrm{P}=0.001\right)$; *PreOp vs. POD 21-27 ( $\mathrm{n}=19$; $\mathrm{P}<0.001)$; and POD 28-34 ( $\mathrm{n}=8 ; \mathrm{P}=\mathrm{ns})$. PreOp, preoperative; PAI-1, plasminogen activator inhibitor-1; POD, postoperative day; ns, not significant.

final cancer stage breakdown was as follows: Stage I $(n=27)$, II $(\mathrm{n}=26)$, III $(\mathrm{n}=34)$ and IV $(\mathrm{n}=4)$.

Association of PAI-1 levels with clinicopathological variables. The median preoperative plasma level of PAI-1 was $17.30 \mathrm{ng} / \mathrm{ml}$ (95\% CI: $15.63-19.78 \mathrm{ng} / \mathrm{ml})$. Compared with the preoperative baseline levels, significantly elevated median levels were observed on POD $1(28.86 \mathrm{ng} / \mathrm{ml} ; 95 \% \mathrm{CI}$ : 25.46-31.22 ng/ml; $\mathrm{P}<0.001 ; \mathrm{n}=91)$, POD $3(18.87 \mathrm{ng} / \mathrm{ml}$; 95\% CI: $17.05-21.78 \mathrm{ng} / \mathrm{ml} ; \mathrm{P}=0.0037 ; \mathrm{n}=86$ ), POD 7-13 $(26.97 \mathrm{ng} / \mathrm{ml} ; 95 \%$ CI: $22.81-28.74 \mathrm{ng} / \mathrm{ml} ; \mathrm{P}<0.001 ; \mathrm{n}=65)$, POD $14-20$ (25.92 ng/ml; $95 \%$ CI: $17.85-35.89 \mathrm{ng} / \mathrm{ml} ; \mathrm{P}=0.001$; $\mathrm{n}=26)$ and POD $21-27$ (22.63 ng/ml;95\% CI: 20.03-30.09ng/ml; $\mathrm{P}<0.001 ; \mathrm{n}=19)$. There was no significant difference between the POD 27-34 and preoperative levels (Fig. 1). The ' $n$ ' for each time point varied for PAI-1 and, therefore, the preoperative median protein values are different at each time point. Because of this, as regards the bar graph figures, at each time point, in addition to a bar showing the postoperative result, there is an adjacent bar (on the left) providing the median preoperative result. There was no significant correlation between age and operative time for plasma PAI-1 levels at all six postoperative time points. No significant differences were found between the male and female groups at any perioperative time point. The percentage increases from the median baseline at each time point were as follows: $66.8 \%$ at POD $1,9.0 \%$ at POD $3,60.6 \%$ at POD $7-13,51.5 \%$ at POD 14-20 and 47.7\% at POD 21-27. Of note, no direct association was observed between advancing cancer stage and preoperative PAI-1 levels, except for the significantly higher levels in the stage II subgroup compared with the stage I subgroup $(\mathrm{P}=0.038)$.

The influence of the incision size (i.e., the extent of abdominal wall trauma) on postoperative PAI-1 levels was also considered. The median PAI-1 levels in the hand-assisted surgery group (mean incision length, $10.2 \pm 3.2 \mathrm{~cm}$ ) were higher compared with those in the laparotomy-assisted surgery group (mean incision length, $6.6 \pm 3.7 \mathrm{~cm}$ ) for 4 weeks 


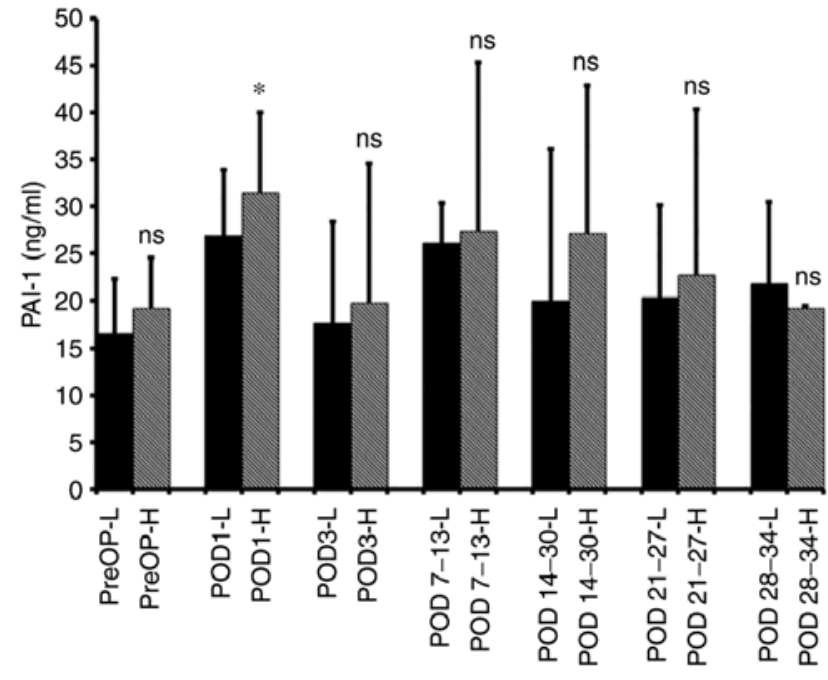

Figure 2. PreOp and postoperative plasma PAI-1 levels were compared between the $\mathrm{L}$ subgroup and the $\mathrm{H}$ subgroup in patients with colorectal cancer using ELISA. PAI-1 levels are expressed as median and $75 \%$ quartile range. PreOp-L (n=59) vs. PreOp-H (n=32; P=ns); ${ }^{*} \mathrm{POD} 1-\mathrm{L}(\mathrm{n}=59)$ vs. POD 1-H $(\mathrm{n}=32 ; \mathrm{P}=0.02)$; POD 3-L ( $\mathrm{n}=55)$ vs. POD $3-\mathrm{H}(\mathrm{n}=31 ; \mathrm{P}=\mathrm{ns})$; POD 7-13-L $(\mathrm{n}=41)$ vs. $\mathrm{POD} 7-13-\mathrm{H}(\mathrm{n}=24 ; \mathrm{P}=\mathrm{ns}) ;$ POD 14-20-L ( $\mathrm{n}=17)$ vs. POD 14-20-H $(\mathrm{n}=9 ; \mathrm{P}=\mathrm{ns})$; POD 21-27-L ( $\mathrm{n}=11)$ vs. POD 21-27-H $(\mathrm{n}=8 ; \mathrm{P}=\mathrm{ns})$; and POD 28-34-L ( $\mathrm{n}=6)$ vs. POD 28-34-H ( $\mathrm{n}=2$; $\mathrm{P}=\mathrm{ns})$. PreOp, preoperative; PAI-1, plasminogen activator inhibitor-1; POD, postoperative day; ns, not significant; L, laparoscopy-assisted procedure; $\mathrm{H}$, hand-assisted procedure.

after surgery; however, the difference was significant only on POD 1 ( $\mathrm{P}=0.02$; Fig. 2).

\section{Discussion}

In patients with CRC undergoing MICR, the plasma levels of PAI-1 were significantly elevated from POD 1 through to POD 27. The percentage change from baseline during the 2 nd through to the 4 th postoperative week ranged from 47.7 to $60.6 \%$. No significant correlation was observed between the abdominal incision length or operative time and the height of the elevations (except for the POD 1 results). If the plasma protein elevation was caused by wound healing, as suggested below, then longer incisions would have been expected to be associated with more pronounced elevations. The failure to demonstrate a direct association between incision length and postoperative blood PAI-1 levels may be associated with the relatively small number of patients in the present study. Another factor may have been the narrow range of incision lengths found in this population of patients who underwent only minimally invasive procedures. As regards the preoperative PAI-1 levels and cancer stage, no significant correlation was found between the pathological cancer stage and blood PAI-1 concentration, except for the significantly higher levels in the stage II subgroup compared with the stage I subgroup $(\mathrm{P}=0.038)$.

The sustained elevation of its plasma levels after surgery place PAI-1 among the growing group of proteins the plasma concentrations of which remain significantly elevated for 2-5 weeks after cancer resection. These proteins include VEGF, Ang-2, PIGF, sVCAM-1, IL-8, MCP-1, CHI3L1, MMP-3 and CXCL-16 (3-5,13-17). These long-duration sustained postoperative elevations are uniquely observed after MICR.
Surgery and anesthesia are well known to transiently alter the blood levels of several proteins, including IL-1, TNF, IL-6, hepatocyte growth factor, fibroblast growth factor, C-reactive protein, IL-4, IL-10 and granulocyte colony-stimulating factor. The majority of these plasma protein elevations resolve in a matter of hours or days. Most of these transient changes are considered to be associated with either the acute inflammatory response (principal mediators, IL-1 $\beta$, TNF and IL-6) or the hypothalamic/pituitary/adrenal axis-generated response to surgical trauma, which results in the production/release of adrenocorticotropic hormone, cortisone, norepinephrine and vasopressin, as well cytokines and other proteins $(34,35)$.

The origin and etiology of the persistent postoperative plasma elevation of PAI-1 and the other aforementioned long-duration proteins are unknown. Although several types of cancer express PAI-1 and these other proteins, CRC is unlikely to be the source of the postoperative plasma elevations observed in this study, as these increases were observed after the primary tumor had been resected. Evidence suggests (36) that wound healing contributes to the elevated blood levels of eight of the proteins with long-duration increases. The levels of these proteins in the fluid from surgical wounds were found to be 3-40 times higher compared with their plasma levels, which were significantly elevated over their preoperative baselines (36). The plasma proteins in question have been hypothesized to follow a concentration gradient from the healing surgical wounds to the bloodstream (31). Given the role of PAI-1 in wound healing, this hypothesis may explain the persistent plasma elevations of PAI-1 after surgery.

PAI-1 inhibits uPA and tPA, thereby regulating plasminrelated fibrinolysis, which is critical to the normal wound healing process (22). Plasmin is a critical protease that breaks down fibrin clots that form soon after wounding during the 'inflammatory' stage of wound healing. Through removal of the fibrin clot, the second phase of wound healing (the proliferative stage) is stimulated; in this phase, fibroblasts generate collagen and tissue fibronectin, which replace the fibrin (23). The modulation of plasmin during wound healing has also been shown to be necessary, as indicated by observations that PAI-1 is expressed in keratinocytes, fibroblasts, and other cells found in healing wounds, and its absence and overexpression affect the wound healing process (37). The role of PAI-1 in wound healing is complex and incompletely understood, as it has been demonstrated by experimental and human evidence that, under different conditions, PAI-1 can both promote and inhibit wound healing (38). Given the role of PAI-1 in wound healing, it is reasonable to infer that the wounds may be the source of the elevated plasma PAI-1 levels observed after surgery.

In addition to regulating fibrinolysis and cell migration, PAI-1 also affects angiogenesis (24). PAI-1 regulates angiogenesis via several mechanisms, including the inhibition of proteolysis and the breakdown of MMPs $(39,40)$. PAI-1 has been shown to exert both pro- and antiangiogenic effects $(38,41)$. PAI-1 in its active form binds vitronectin, a glycoprotein that is found in both the plasma and the ECM, and plays a key role in cell adhesion via integrin binding (41). When PAI-1 is bound to vitronectin, the integrin adhesion site on vitronectin is blocked, thus diminishing EC migration from the circulation to the periphery and hindering angiogenesis (41). In addition, PAI-1 directly inhibits proteinases 
that inhibit vessel formation (41). By inhibiting EC migration to vitronectin, PAI-1 promotes EC binding to fibronectin (a critical cell adhesion glycoprotein) in the wound, thereby facilitating angiogenesis. Thus, the composition of the ECM (vitronectin vs. fibronectin balance) may determine whether the net effect of PAI-1 is pro- or antiangiogenic. Of note, in response to hypoxia, the transcription of PAI-1 increases via elevated PAI-1 promoter activity and genistein-sensitive tyrosine kinase-mediated phosphorylation of transcription factors (42). As tumors have high fibronectin levels and a hypoxic stroma, PAI-1 promotes the migration of ECs away from the well-oxygenated, vitronectin-rich extravascular space and into the hypoxic, fibronectin-rich tumor (24). Thus, PAI-1 may promote angiogenesis in tumors while inhibiting new vessel formation in well-oxygenated environments; high PAI-1 levels during the first month after MICR may stimulate tumor angiogenesis in residual tumor deposits. The results of an experimental study suggested that PAI-1 may also affect VEGF levels in wounds. Chan et al (37) compared skin wound healing between PAI-1 knockout (PAI-1 ${ }^{-/}$) and wild-type (WT) mice $\left(\mathrm{PAI}-1^{+/+}\right)$. Whereas VEGF expression in the connective tissue of the wounds in WT mice was readily observed, VEGF was poorly expressed in the wounds of PAI-1 knockout mice.

PAI-1 may also influence tumor cell growth. Cell cycle progression, a hallmark of cancer, is regulated by cyclins and cyclin-dependent kinases (CDKs) that control whether a cell can progress through the cell cycle and ultimately replicate (43). PAI-1-deficient tumor cells cannot progress through G1 phase into the $\mathrm{S}$ phase, and they exhibit elevated levels of p53 and diminished levels of G1-phase transition complexes (cyclin D3/CDK4/6 and cyclin E/CDK2), thus suggesting that PAI-1 promotes cell cycle progression and tumor cell proliferation (44). In addition, PAI-1 modulates uPA and extracellular cell signaling molecules and interactors. The effect of this modulated interaction is sustained Ras/MAPK1 pathway activity, which promotes cell proliferation (45).

In addition to promoting cell proliferation, PAI-1 inhibits spontaneous apoptosis (46). Knockout of PAI-1 results in increased plasmin activity, which in turn facilitates spontaneous apoptosis, as plasmin cleaves FasL and generates a pro-apoptotic FasL fragment (40). PAI-1 thereby protects ECs and potentially tumor cells from Fas/FasL-mediated apoptosis (47). PAI-1 also inhibits the activation and activity of caspase-3, thus promoting apoptosis via the Fas/FasL pathway (48). By attenuating apoptotic signaling, PAI-1 reduces the tumor response to chemotherapy $(46,49)$.

Whether PAI-1 promotes tumor cell migration and metastasis remains controversial. In vivo experiments have demonstrated both pro- and anti-metastatic effects. Higher plasma levels of PAI-1 were found to be correlated with larger tumors and more frequent liver metastases in CRC, and its silencing reduces the expression of MMPs, thus preventing the degradation of ECM and cell mobility (33). By contrast, overexpression of PAI-1 has been found to suppress cellular invasion and liver metastasis in a pancreatic cancer cell line (50). The different conclusions may, in part, be attributed to differences in the experimental protocols, tumor cell lines, inoculation methods, use of immunocompetent vs. immunocompromised or knockout vs. overexpressing mice, and examination of macro- vs. micrometastasis (51).
Given the correlation between increased levels of PAI-1 and worse oncological outcomes, researchers are striving to formulate pharmacological inhibitors of PAI-1; the majority of studies have been focused on forcing a conformational change of PAI-1 into its inactive form $(52,53)$. PAI-039 (tiplaxtinin) is currently in clinical trials for Alzheimer's disease and has been reported to suppress the growth of bladder and cervical cancers (54). SK-216 has been shown to notably reduce the number of intestinal polyps in a mouse model with a defect in the adenomatous polyposis coli gene (55). Another small-molecule inhibitor (TM5275) was shown to block ovarian cancer cell proliferation by causing G2/M cell cycle arrest (56). However, to the best of our knowledge, no PAI-1 inhibitor is currently being used in clinical trials for cancer treatment.

There were several substantial limitations to the present study. First, the number of post-hospital discharge time points was considerably lower than the initial number of patients and decreased at each successive time point. After the initial postoperative office visit, the majority of the patients were not seen again in the first month, and some patients refused additional blood sampling. Since obtaining the late blood samples on the same postoperative days was impossible for logistical reasons, it was necessary to 'bundle' the specimens for postoperative weeks 2, 3, 4 and 5 and consider them as single time points. Furthermore, the size of the study and the lack of long-term outcome data prevent a meaningful correlation of PAI-1 levels and cancer outcomes. A more extensive and comprehensive study would likely shed light on these issues. Another shortcoming of this study is that the CRCs from the study patients were not evaluated for PAI-1 expression.

PAI-1 belongs to the group of proteins the postoperative blood levels of which remain elevated for 3-5 weeks after MICR. The clinical ramifications of the surgery-associated long-duration plasma protein changes are unknown. All nine proteins on the list provided above plus PAI-1 serve key roles in the complex process of angiogenesis, beyond their numerous other effects. Moreover, as mentioned, several studies have provided in vitro evidence that plasma collected from the 2nd and 3rd weeks post-MICR increased EC invasion, migration and proliferation beyond that observed in EC cultures into which preoperative plasma from the same patients was added $(28,49)$. These findings suggest that the net effects of the surgery-related changes to blood composition transiently render the plasma proangiogenic during the first month after surgery. Despite being unproven, a concern exists that tumor angiogenesis and, therefore, tumor growth may be stimulated during the first month after surgery in patients who have residual micro-metastases following resection of the primary tumor. If this is the case, then the postoperative period is a perilous time for patients with cancer who harbor metastases. The development of anticancer treatments that could be used perioperatively would be a logical next step.

In conclusion, the findings of the present study demonstrated significant and persistent elevations of plasma PAI-1 levels over the preoperative baseline for 1 month after MICR for CRC. Although the etiology of these postoperative changes was not assessed in the present study, it was hypothesized that the acute inflammatory response may account for the early 
PAI-1 elevations, whereas the later postoperative elevations may be associated with wound healing. Further studies are required to determine the cause and possible ramifications of these changes.

\section{Acknowledgements}

Not applicable.

\section{Funding}

The present study was supported by a generous donation (grant no. SL55002012 from the Thompson Family Foundation to the Division of Colon and Rectal Surgery, Department of Surgery, Mount Sinai West Hospital, New York.

\section{Availability of data and materials}

The datasets generated and/or analyzed during the current study, other than those included in the article, are not publicly available due to protection of patient privacy and biosecurity reasons; all other data generated or analyzed during this study are included in this published article.

\section{Authors' contributions}

HMCSK and RLW contributed to the design, conception and statistical analysis; PA, DNG, EP, XY and VC contributed to the study design, data collection, sample preparation, analysis and interpretation; HMCSK and XY confirm the authenticity of all the raw data. HMCSK, RLW and AS contributed to conducting of experiments, data interpretation and critical revision of the manuscript. All authors were involved in drafting the manuscript, made revisions, and approved the article's final version.

\section{Ethics approval and consent to participate}

The present study was conducted by using material collected from patients who consented preoperatively to participate in the Mount Sinai West Colorectal service's IRB-approved general tissue and data banking protocol (reference no.: GCO1: 16-2619-Institutional Review Board of the Mount Sinai School of Medicine, New York, USA; and reference no.: AAAA4473-Institutional Review Board of the Columbia University Medical Center, New York, USA).

\section{Patient consent for publication}

Written informed consent was obtained from all participating patients.

\section{Competing interests}

The authors declare that they have no competing interests.

\section{References}

1. Platell CF: Changing patterns of recurrence after treatment for colorectal cancer. Int J Colorectal Dis 22: 1223-1231, 2007.
2. Coffey JC, Wang JH, Smith MJ, Bouchier-Hayes D, Cotter TG and Redmond HP: Excisional surgery for cancer cure: Therapy at a cost. Lancet Oncol 4: 760-768, 2003.

3. Kumara HM, Feingold D, Kalady M, Dujovny N, Senagore A, Hyman N, Cekic V and Whelan RL: Colorectal resection is associated with persistent proangiogenic plasma protein changes: Postoperative plasma stimulates in vitro endothelial cell growth, migration, and invasion. Ann Surg 249: 973-977, 2009.

4. Shantha Kumara HM, Myers EA, Herath SA, Jang JH, Njoh L, Yan X, Kirchoff D, Cekic V, Luchtefeld M and Whelan RL: Plasma monocyte chemotactic protein-1 remains elevated after minimally invasive colorectal cancer resection. World J Gastrointest Oncol 6: 413-419, 2014.

5. Shantha Kumara HM, Gaita D, Miyagaki H, Yan X, Hearth SA, Njoh L, Cekic V and Whelan RL: Plasma chitinase 3-like 1 is persistently elevated during first month after minimally invasive colorectal cancer resection. World J Gastrointest Oncol 8: 607-614, 2016.

6. Kumara HMCS, Bellini GA, Caballero OL, Herath SAC, Su T, Ahmed A, Njoh L, Cekic V and Whelan RL: P-Cadherin (CDH3) is overexpressed in colorectal tumors and has potential as a serum marker for colorectal cancer monitoring. Oncoscience 4: 139-147, 2017.

7. Shantha Kumara HM, Kirman I, Feingold D, Cekic V, Nasar A, Arnell T, Balik E, Hoffman A, Baxter R, Conte S and Whelan RL: Perioperative GMCSF limits the proangiogenic plasma protein changes associated with colorectal cancer resection. Eur J Surg Oncol 35: 295-301, 2009.

8. Carter JJ, Feingold DL, Oh A, Kirman I, Wildbrett P, Stapleton G, Asi Z, Fowler R, Bhagat G, Huang EH, et al: Perioperative immunomodulation with Flt3 kinase ligand or a whole tumor cell vaccine is associated with a reduction in lung metastasis formation after laparotomy in mice. Surg Innov 13: 41-47, 2006.

9. Smith I, Robertson J, Kilburn L, Wilcox M, Evans A, Holcombe C, Horgan K, Kirwan C, Mallon E, Sibbering M, et al: Long-term outcome and prognostic value of Ki67 after perioperative endocrine therapy in postmenopausal women with hormone-sensitive early breast cancer (POETIC): An open-label, multicentre, parallel-group, randomised, phase 3 trial. Lancet Oncol 21: 1443-1454, 2020.

10. O'Reilly MS, Holmgren L, Shing Y, Chen C, Rosenthal RA, Moses M, Lane WS, Cao Y, Sage EH and Folkman J: Angiostatin: A novel angiogenesis inhibitor that mediates the suppression of metastases by a Lewis lung carcinoma. Cell 79: 315-328, 1994.

11. Kirman I, Cekic V, Poltaratskaia N, Asi Z, Bessler M, Huang EH, Forde KA and Whelan RL: Plasma from patients undergoing major open surgery stimulates in vitro tumor growth: Lower insulin-like growth factor binding protein 3 levels may, in part, account for this change. Surgery 132: 186-192, 2002.

12. Allendorf JD, Bessler M, Horvath KD, Marvin MR, Laird DA and Whelan RL: Increased tumor establishment and growth after open vs. laparoscopic surgery in mice may be related to differences in postoperative T-cell function. Surg Endosc 13: 233-235, 1999.

13. Shantha Kumara HM, Cabot JC, Yan X, Herath SA, Luchtefeld M, Kalady MF, Feingold DL, Baxter R and Whelan RL: Minimally invasive colon resection is associated with a persistent increase in plasma PIGF levels following cancer resection. Surg Endosc 25: 2153-2158, 2011.

14. Shantha Kumara HM, Tohme ST, Herath SA, Yan X, Senagore AJ, Nasar A, Kalady MF, Baxter R and Whelan RL: Plasma soluble vascular adhesion molecule-1 levels are persistently elevated during the first month after colorectal cancer resection. Surg Endosc 26: 1759-1764, 2012.

15. Shantha Kumara HM, Gaita DJ, Miyagaki H, Yan X, Herath SA, Cekic V and Whelan RL: Minimally invasive colorectal resection is associated with significantly elevated levels of plasma matrix metalloproteinase 3 (MMP-3) during the first month after surgery which may promote the growth of residual metastases. Surg Endosc 28: 3322-3328, 2014.

16. Shantha Kumara HMC, Pettke E, Shah A, Yan X, Cekic V, Downing MA, Gandhi ND and Whelan RL: Plasma levels of the proangiogenic protein CXCL16 remains elevated for 1 month after minimally invasive colorectal cancer resection. World J Surg Oncol 16: 132, 2018.

17. Shantha Kumara HMC, Sutton E, Bellini GA, Yan X, Cekic V, Gandhi ND and Whelan RL: Plasma interleukin-8 levels are persistently elevated for 1 month after minimally invasive colorectal resection for colorectal cancer. Mol Clin Oncol 8: 471-476, 2018. 
18. Belizon A, Balik E, Horst P, Feingold D, Arnell T, Azarani T, Cekic V, Skitt R, Kumara S and Whelan RL: Persistent elevation of plasma vascular endothelial growth factor levels during the first month after minimally invasive colorectal resection. Surg Endosc 22: 287-297, 2008.

19. Shantha Kumara HM, Kirchoff D, Naffouje S, Grieco M, Herath SA, Dujovny N, Kalady MF, Hyman N, Njoh L and Whelan RL: Plasma from the second and third weeks after open colorectal resection for cancer stimulates in vitro endothelial cell growth, migration, and invasion. Surg Endosc 26: 790-795, 2012 .

20. Shantha Kumara HM, Grieco MJ, Caballero OL, Su T, Ahmed A, Ritter E, Gnjatic S, Cekic V, Old LJ, Simpson AJ, et al: MAGE-A3 is highly expressed in a subset of colorectal cancer patients. Cancer Immun 12: 16, 2012.

21. Shantha Kumara H, Kirchoff D, Caballero OL, Su T, Ahmed A Herath SA, Njoh L, Cekic V, Simpson AJ, Cordon-Cardo C and Whelan RL: Expression of the cancer testis antigen IGF2BP3 in colorectal cancers; IGF2BP3 holds promise as a specific immunotherapy target. Oncoscience 2: 607-614, 2015.

22. Shetty S and Idell S: FIBRINOLYSIS I Plasminogen Activator and Plasmin. In: Encyclopedia of Respiratory Medicine. Laurent GJ and Shapiro SD (eds). Academic Press, pp205-210, 2006.

23. Wilkinson HN and Hardman MJ. Wound healing: Cellular mechanisms and pathological outcomes. Open Biol 10: 200223, 2020.

24. Isogai C, Laug WE, Shimada H, Declerck PJ, Stins MF, Durden DL, Erdreich-Epstein A and DeClerck YA: Plasminogen activator inhibitor-1 promotes angiogenesis by stimulating endothelial cell migration toward fibronectin. Cancer Res 61 : 5587-5594, 2001.

25. Dellas C and Loskutoff DJ: Historical analysis of PAI-1 from its discovery to its potential role in cell motility and disease. Thromb Haemost 93: 631-640, 2005.

26. Angenete E, Langenskiöld M, Palmgren I, Falk P, Oresland T and Ivarsson ML: uPA and PAI-1 in rectal cancer-relationship to radiotherapy and clinical outcome. J Surg Res 153: 46-53, 2009.

27. Lu JJ, Guo H, Gao B, Zhang Y, Lin QL, Shi J, Liu JJ and Liu J: Prognostic value of urokinase plasminogen activator system in non-small cell lung cancer: A systematic review and metaanalysis. Mol Clin Oncol 8: 127-132, 2018.

28. Harbeck N, Thomssen C, Berger U, Ulm K, Kates RE, Höfler H, Jänicke $\mathrm{F}$, Graeff $\mathrm{H}$ and Schmitt $\mathrm{M}$ : Invasion marker PAI-1 remains a strong prognostic factor after long-term follow-up both for primary breast cancer and following first relapse. Breast Cancer Res Treat 54: 147-157, 1999.

29. Harbeck N, Schmitt M, Meisner C, Friedel C, Untch M, Schmidt M, Sweep CG, Lisboa BW, Lux MP, Beck T, et al: Ten-year analysis of the prospective multicentre Chemo-NO trial validates American Society of Clinical Oncology (ASCO)-recommended biomarkers uPA and PAI-1 for therapy decision making in node-negative breast cancer patients. Eur J Cancer 49: 1825-1835, 2013.

30. Suh YS, Yu J, Kim BC, Choi B, Han TS, Ahn HS, Kong SH, Lee HJ, Kim WH and Yang HK: Overexpression of plasminogen activator inhibitor-1 in advanced gastric cancer with aggressive lymph node metastasis. Cancer Res Treat 47: 718-726, 2015.

31. Berger DH: Plasmin/plasminogen system in colorectal cancer. World J Surg 26: 767-771, 2002.

32. Nielsen HJ, Christensen IJ, Sørensen S, Moesgaard F and Brünner N: Preoperative plasma plasminogen activator inhibitor type-1 and serum C-reactive protein levels in patients with colorectal cancer. The RANX05 colorectal cancer study group. Ann Surg Oncol 7: 617-623, 2000.

33. Chen H, Peng H, Liu W, Sun Y, Su N, Tang W, Zhang X, Wang J, Cui L, Hu P and Liu S: Silencing of plasminogen activator inhibitor-1 suppresses colorectal cancer progression and liver metastasis. Surgery 158: 1704-1713, 2015.

34. Desborough JP: The stress response to trauma and surgery Br J Anaesth 85: 109-117, 2000.

35. Kany S, Vollrath JT and Relja B: Cytokines in inflammatory disease. Int J Mol Sci 20: 6008, 2019.

36. Shantha Kumara H, Yan XH, Pettke E, Cekic V, Gandhi ND, Bellini GA and Whelan RL: Plasma and wound fluid levels of eight proangiogenic proteins are elevated after colorectal resection. World J Gastrointest Oncol 11: 470-488, 2019.

37. Chan JC, Duszczyszyn DA, Castellino FJ and Ploplis VA: Accelerated skin wound healing in plasminogen activator inhibitor-1-deficient mice. Am J Pathol 159: 1681-1688, 2001.
38. Maquerlot F, Galiacy S, Malo M, Guignabert C, Lawrence DA, d'Ortho MP and Barlovatz-Meimon G: Dual role for plasminogen activator inhibitor type 1 as soluble and as matricellular regulator of epithelial alveolar cell wound healing. Am J Pathol 169: 1624-1632, 2006.

39. Devy L, Blacher S, Grignet-Debrus C, Bajou K, Masson V, Gerard R.D, Gils A, Carmeliet G, Carmeliet P, Declerck PJ, et al: The pro- or antiangiogenic effect of plasminogen activator inhibitor 1 is dose dependent. FASEB J 16: 147-154, 2002.

40. Bajou K, Peng H, Laug WE, Maillard C, Noel A, Foidart JM, Martial JA and DeClerck YA: Plasminogen activator inhibitor-1 protects endothelial cells from FasL-mediated apoptosis. Cancer Cell 14: 324-334, 2008.

41. Stefansson S, Petitclerc E, Wong MK, McMahon GA, Brooks PC and Lawrence DA: Inhibition of angiogenesis in vivo by plasminogen activator inhibitor-1. J Biol Chem 276: 8135-8141, 2001.

42. Uchiyama T, Kurabayashi M, Ohyama Y, Utsugi T, Akuzawa N, Sato M, Tomono S, Kawazu S and Nagai R: Hypoxia induces transcription of the plasminogen activator inhibitor-1 gene through genistein-sensitive tyrosine kinase pathways in vascular endothelial cells. Arterioscler Thromb Vasc Biol 20: 1155-1161, 2000.

43. Casimiro MC, Crosariol M, Loro E, Li Z and Pestell RG: Cyclins and cell cycle control in cancer and disease. Genes Cancer 3: 649-657, 2012.

44. Giacoia EG, Miyake M, Lawton A, Goodison S and Rosser CJ: PAI-1 leads to G1-phase cell-cycle progression through cyclin D3/cdk4/6 upregulation. Mol Cancer Res 12: 322-334, 2014.

45. Webb DJ, Thomas KS and Gonias SL: Plasminogen activator inhibitor 1 functions as a urokinase response modifier at the level of cell signaling and thereby promotes MCF-7 cell growth. J Cell Bio 152: 741-752, 2001.

46. Kwaan HC, Wang J, Svoboda K and Declerck PJ: Plasminogen activator inhibitor 1 may promote tumour growth through inhibition of apoptosis. Br J Cancer 82: 1702-1708, 2000.

47. Fang H, Placencio VR and DeClerck YA: Protumorigenic activity of plasminogen activator inhibitor-1 through an antiapoptotic function. J Natl Cancer Inst 104: 1470-1484, 2012.

48. Chen Y, Kelm RJ Jr, Budd RC, Sobel BE and Schneider DJ: Inhibition of apoptosis and caspase- 3 in vascular smooth muscle cells by plasminogen activator inhibitor type-1. J Cell Biochem 92: 178-188, 2004.

49. Rømer MU, Larsen L, Offenberg H, Brünner $\mathrm{N}$ and Lademann UA: Plasminogen activator inhibitor 1 protects fibrosarcoma cells from etoposide-induced apoptosis through activation of the PI3K/Akt cell survival pathway. Neoplasia 10: 1083-1091, 2008.

50. Inoue M, Sawada T, Uchima Y, Kimura K, Nishihara T, Tanaka H, Yashiro M, Yamada N, Ohira M and Hirakawa K: Plasminogen activator inhibitor-1 (PAI-1) gene transfection inhibits the liver metastasis of pancreatic cancer by preventing angiogenesis. Oncol Rep 14: 1445-1451, 2005.

51. Kubala MH and DeClerck YA: The plasminogen activator inhibitor-1 paradox in cancer: A mechanistic understanding. Cancer Metastasis Rev 38: 483-492, 2019.

52. Placencio VR and DeClerck YA: Plasminogen activator inhibitor-1 in cancer: Rationale and insight for future therapeutic testing. Cancer Res 75: 2969-2974, 2015.

53. Fortenberry YM: Plasminogen activator inhibitor-1 inhibitors: A patent review (2006-present). Expert Opin Ther Pat 23: 801-815, 2013

54. Gomes-Giacoia E, Miyake M, Goodison S and Rosser CJ: Targeting plasminogen activator inhibitor-1 inhibits angiogenesis and tumor growth in a human cancer xenograft model. Mol Cancer Ther 12: 2697-2708, 2013.

55. Mutoh M, Niho N, Komiya M, Takahashi M, Ohtsubo R, Nakatogawa K, Ueda K, Sugimura T and Wakabayashi K: Plasminogen activator inhibitor-1 (Pai-1) blockers suppress intestinal polyp formation in Min mice. Carcinogenesis 29: 824-829, 2008.

56. Mashiko S, Kitatani K, Toyoshima M, Ichimura A, Dan T, Usui T, Ishibashi M, Shigeta S, Nagase S, Miyata T and Yaegashi N: Inhibition of plasminogen activator inhibitor-1 is a potential therapeutic strategy in ovarian cancer. Cancer Biol Ther 16: 253-260, 2015

This work is licensed under a Creative Commons Attribution-NonCommercial-NoDerivatives 4.0 International (CC BY-NC-ND 4.0) License. 